\title{
Form, Function and Palaeobiology: Preface
}

\author{
Sergio F. Vizcaíno ${ }^{1,2}$, Euan N. K. Clarkson ${ }^{3}$ and Brigitte Schoenemann ${ }^{4,5}$ \\ ${ }^{1}$ CONICET, Facultad de Ciencias Naturales y Museo, Universidad Nacional de La Plata, Argentina. \\ ${ }^{2}$ División Paleontología Vertebrados, Unidades de Investigación Anexo Museo FCNyM-UNLP, Av. 60 y 122, \\ 1900, La Plata, Argentina. \\ ${ }^{3}$ Grant Institute, School of Geosciences, The King's Buildings, University of Edinburgh, West Mains Road, \\ Edinburgh EH9 3JW, Scotland, UK. \\ ${ }^{4}$ University of Cologne, Institute of Zoology, Department of Animal Physiology, Biocenter Cologne, \\ Zülpicherstrasse 47b, D-50674 Köln, Germany. \\ ${ }^{5}$ University of Cologne, Institute of Biology Education (Zoology), Herbert-Lewinstrasse 10, D-50931 Cologne, \\ Germany.
}

This Special Issue of the Earth \& Environmental Science Transactions of The Royal Society of Edinburgh comprises a collection of papers presented at the Symposium "Form, Function and Palaeobiology", chaired by SFV and ENKC during the IV International Palaeontological Congress held in Mendoza, Argentina, September 28-October 3, 2014.

The Symposium included 32 oral and poster contributions, encompassing a wide variety of subjects, from plants to invertebrates and vertebrates, from widespread temporal and geographic ranges and with a broad range of methodological scopes, by authors from a more than interesting diversity of countries (and continents), such as Argentina, Australia, Brazil, China, Germany, Great Britain, Japan, Spain, Sweden, Switzerland and the USA, just considering the first authors. Twelve of the original 32 contributions were submitted to this volume and its content is more biased to vertebrates and South America (and mostly Argentina), than originally expected by us.

Despite this constraint, the papers in this volume cover a wide range of topics and are written by both experts in their field and young researchers, who are bringing 'fresh air' to palaeontological research in South America, focusing more and more on palaeobiology. Using modern devices, methodologies and approaches, they are dealing with issues that were previously treated in a more intuitive way by palaeontologists who had to solve systematic, phylogenetic and biostratigraphic problems. As a consequence, the reconstruction of the biology of extinct taxa is becoming more the result of testing and generating hypotheses than of inductivism.

Due to the wide scope of the papers, they are arranged by broad issues. This volume starts with two articles on invertebrates. The first, by Schoenemann \& Clarkson, is a review of what we know about vision in early animals, based on fossilised eyes. In the second, Echevarría et al. study the shell/ ligament system in bivalves, contributing to the relatively less developed studies in functional morphology in extinct invertebrates as compared to vertebrates.

Then there are three articles on non-avian archosaurs: Candeiro et al. report dental wear in relation to feeding, in dinosaurs from Brazil; Bona et al. study the neuroanatomy of a Miocene gavial from Argentina, considering morphological variation in extinct and extant relatives; and Herrera et al. consider alternative hypotheses on the reproductive strategies of mosasaurs, providing a superb discussion on epistemological approaches to infer behaviour in extinct forms without clear extant analogues.

The remaining articles are on Cenozoic South American birds and mammals. Degrange studies the proportion of the limb bones of terror birds to envision their styles of ground locomotion, Echarri et al. analyse the mandible morphology of marsupials, and Toledo et al. consider the influence of body size on the different biological traits of sloths and anteaters. Cassini et al. present an analysis of the relationship between teeth dimensions and body size in early Miocene notoungulates, and Muñoz et al. perform a 3-D study of the articular surfaces in relation to the ecomorphology of small mammals, as represented by early Miocene notungulates. Finally, Tarquini et al. and Ercoli provide the first ecomorphological and morphofunctional studies on late Miocene-early Pleistocene raccoons and Pleistocene weasels.

The Editors would like to thank all those who contributed to the Symposium, and the organisers of the IV International Palaeontological Congress. We are indebted to the authors who contributed final articles to this Special Issue of the Earth \& Environmental Science Transactions of The Royal Society of Edinburgh. Also to Mike Benton as the Overseeing Editor for the journal, the reviewers and, most particularly, to Vicki Hammond for all the work done to make the publication of this volume possible. 
